around the body of the uterus and also one round each of the horns above the ovary, and excise the intervening portion.

The external wound was treated antiseptically, and, although the animal was somewhat dull and off her feed, she eventually made a good recovery.

CASE 2.-For this I am indebted to Mr Walder, of Class D, who performed the operation during the Whitsuntide vacation. The patient was a spaniel, aged three years, in œstrum. The seat of operation was the median line, the ovaries and horns being ligatured with aseptic catgut and removed ; the horns were taken off just below their junction with the body. The wound suppurated, but eventually the animal made a good recovery.

CASE 3.- I $5^{\text {th }}$ June. Cat, aged about two years. The whole of the uterus from above the ovaries to the commencement of the body was removed, the contents consisting of three foetuses between seven and eight weeks old. Aseptic catgut ligatures were placed above each ovary and around the body of the uterus before incision. The external wound, made in the median line, was sutured and dressed with iodoform and collodion, and had quite healed in three days, the appetite remaining good throughout.

\title{
JAUNDICE IN THE DOG, AND OTHER CASES,
}

By P. S. Howard, M.R.C.V.S., Royal Veterinary Collegre, London.

CASE I. Janndice and Intussusception in the Dog--An aged fox-terrier dog was brought to the Clinique suffering from jaundice, the visible mucous membranes being very yellow in appearance.

In the treatment doses of calomel (gr. ij.) were administered once a day in the form of a pill; a light nutritious diet was also prescribed. At the expiration of a week the patient seemed to be recovering, the yellowness of the membranes being less marked, and the appetite showing signs of improvement.

The same treatment was continued during the second week, at the end of which a relapse occurred and the animal died.

On making a post-mortem examination the liver was found to be congested, the gall bladder contained a small quantity of bile, and the common duct was not markedly distended. In the first portion of the small intestine, about 8 inches from the pylorus, there was an intussusception $3 \frac{1}{2}$ inches long; from its appearance the lesion must have been recent, and therefore was probably not the cause of the jaundice.

CASE II. Rupture of Liver in the Dog:-The body of an average sized bull-terrier dog, about three years old, was brought to the Clinique for post-inortem examination.

The history was that the dog had suddenly died without any symptoms having been noticed.

It was observed that the visible mucous membranes were abnormally pallid in appearance. When the abdomen was incised there was an escape of clotted blood, and on further examination the abdominal cavity was found to be filled with the same material.

A rupture with lacerated edges was present at the lower border of 
the liver in close proximity to the portal fissure; a clot of blood occupied the space between the ruptured surfaces.

The liver was in a state of advanced fatty infiltration, and this probably predisposed to the rupture; at the same time no direct evidence of a blow or other exciting cause was obtainable.

CASE III. Polypus in Eustachian Tube of the Cat.-A cat about eleven years old was brought to be destroyed.

The owner stated that the cat had been sneezing constantly for nine months and was gradually becoming worse.

The head was sawn in haltes after death, and a growth about the size of a small pea was discovered projecting into the pharynx from the left Eustachian tube.

On slitting up the tube the pedicle was found to be attached to it about half an inch from the pharyngeal opening.

It may be mentioned that the ear of the same side was badly affected with otorrhoea, but on following up the Eustachian tube to the middle ear no connection between the two conditions could be discovered.

CASE IV. Sarcoptic Mange in the Fowl.-A fowl was brought with a scaly affection of the legs, and also to a slight extent of the head.

The lesions consisted of crusts from half an inch to two-thirds of an inch in thickness; the exterior of these was dry and grey in colour, while their interior was yellow and moist. On closer inspection their surface showed a number of very minute granules about the size of a pin's point.

When the scales were stripped off theles a bleeding surface was. exposed. The scales covered the foot and the whole of that portion. of the leg which was devoid of feathers.

On examining the scales microscopically numerous parasites were found; these were identified as belonging to the genus sarcoptes. The females are oval in shape, and their legs are so short as to appear like small dots around the margin of the parasite. The two posterior pairs of legs do not project from beneath the parasite at all. The males are about quarter the size of the females, with much longer legs in proportion to their size.

Their movements are nothing like so rapid as in many other varieties of the sarcoptes ; they resemble the other varieties of this genus also in that the females burrow, while the males are found exclusively on the surface of the crusts.

The treatment of this disease must be both preventive and curative ; in the former it is necessary to isolate all the affected fowls, and in the latter to deal with the lesions, this being quite successful if actively carried out. The scales should be removed by either peeling them off, or better still by soaking them in warm water and soap or some alkaline solution, such as carbonate of soda, after which one of the ordinary dressings for mange should be applied.

Since the above case came into the Clinique, I have seen several additional ones, although they have not been so severe in nature. The disease seems to be quite familiar to fowl-keepers, although, at the same time, its true nature is not generally recognised by them. 